\title{
PERANCANGAN SISTEM MONITORING MATERIAL SUBMERGED SCRAPER CONVEYOR PT PJB UP PAITON 1-2 BERBASIS IOT
}

\author{
Agustian Lukmanul Hakim ${ }^{1}$, \\ Program Studi Teknik Elektro Universitas Nurul Jadid \\ Email: agustian.lukmanh@gmail.com \\ Ilmi Rizki Imaduddin ${ }^{1}$ \\ Program Studi Teknik Elektro Universitas Nurul Jadid \\ Email: ilmi.eeunuja@gmail.com \\ Moh. Bachrudin ${ }^{1}$ \\ Program Studi Teknik Elektro Universitas Nurul Jadid \\ Email: udintf06@gmail.com
}

\begin{abstract}
S : Submerged Scraper Conveyor (SSC) is one of the main equipment at PT PJB UP Paiton 1-2. Serves to transport bottom ash material produced by the boiler to the chute dump truck or to the bottom ash silo through the conveyor belt. The change in the use of coal from medium rank coal to low rank coal causes the volume of bottom ash material produced by the boiler to increase, so there are several problems including material overload, blockage in the transfer chute and damage to the crusher. Therefore, in this study, the design of a material monitoring system in SSC was carried out using the ubidots IoT platform. Researchers used ultrasonik sensors to measure the level of material on the scraper and then visualized it on a graph which can be accessed via the website. Then a warning is added via telegram when the material level is above $50 \mathrm{~cm}$. Based on the test results, it can be concluded that the monitoring system that has been designed can display material level graphs stably with an accuracy of $\pm 2 \mathrm{~cm}$ on the online ubidots platform and successfully sends notifications via telegram when material levels are detected. $>50 \mathrm{~cm}$.

Keyword: Scraper Conveyor; Material Monitoring; Internet of Things (IoT); Ubidots
\end{abstract}

\begin{abstract}
ABSTRAK: Submerged Scraper Conveyor (SSC) merupakan salah satu perlengkapan utama di PT PJB UP Paiton 1-2. Berfungsi untuk mengangkut material bottom ash yang dihasilkan oleh boiler ke chute dump truck atau ke bottom ash silo melalui conveyor belt. Perubahan penggunaan batubara dari batubara medium rank ke batubara low rank menyebabkan volume material bottom ash yang dihasilkan boiler menjadi semakin meningkat, sehingga terdapat beberapa permasalahan diantaranya material overload, penyumbatan pada transfer chute dan kerusakan pada crusher. Oleh karena itu, pada penelitian ini dilakukan perancangan sistem monitoring material di SSC dengan menggunakan platform ubidots IoT. Peneliti menggunakan sensor ultrasonik untuk mengukur level material pada scraper kemudian divisualisasikan pada grafik yang dapat diakses melalui website. Kemudian ditambahkan Peringatan melalui telegram saat level material di atas $50 \mathrm{~cm}$. Berdasarkan hasil pengujian dapat disimpulkan bahwa sistem monitoring yang telah dirancang dapat menampilkan grafik level material secara stabil dengan akurasi $\pm 2 \mathrm{~cm}$ pada platform ubidots secara online dan berhasil mengirimkan notifikasi melalui telegram ketika terdeteksi level material $>50 \mathrm{~cm}$
\end{abstract}

Kata Kunci: Konveyor Skraper; Monitoring Material; Internet of Things (IoT); Ubidots

\section{PENDAHULUAN}

$\mathrm{D}$ tahun 2018 PT Pembangkitan Jawa Bali (PJB) mengimplementasikan program coal switching pada PLTU Paiton unit 1-2, yaitu program peralihan penggunaan batu bara dari kalori $6000 \mathrm{kcal} / \mathrm{kg}$ menuju $4.200 \mathrm{kcal} / \mathrm{kg}$ di tahun 2022[1]. Perubahan spesifikasi batubara yang dibakar berdampak pada operasi peralatan, salah satunya pada submerged scraper conveyor (SSC)[2].

SSC berfungsi mengangkut material bottom ash yang dihasilkan boiler, menuju chute pembuangan dump truck atau ke bottom ash silo melalui belt conveyor[3]. Penggunaan batubara kalori rendah menyebabkan volume material bottom ash meningkat sehingga menambah beban kerja dari SSC. Peningkatan volume material bottom ash dapat menyebabkan beberapa permasalahan seperti SSC trip karena overload, buntu pada transfer chute dan kerusakan pada grinder.

SSC merupakan peralatan yang harus beroperasi 24 jam bersamaan dengan operasi boiler yang terus menerus menghasilkan material bottom ash[4], sehingga gangguan pada SSC akan sangat mempengaruhi kehandalan operasional unit. Upaya yang telah dilakukan bidang produksi adalah peningkatan intensitas patrol check dan pengendalian pola shoot blower oleh operator Center Control Room (CCR).

Operator lokal mengecek kondisi material bottom ash pada scraper SSC di rentang waktu tertentu secara manual dan melaporkannya pada operator $C C R$, kemudian dengan itu pola operasi shoot blower disesuaikan. Bidang kontrol instrumen juga telah melakukan modifikasi pada tampilan Human Machine Interface (HMI) SSC di CCR Ash Handling, yaitu penambahan pembacaan torsi, namun penampilannya masih terbatas pada panel lokal dan CCR Ash Handling[2].

1 Universitas Nurul Jadid, Karanganyar, Kecamatan Paiton, Kabupaten Probolinggo, Jawa Timur 67292 
Internet of Things (IoT) menggunakan beberapa teknologi yang secara garis besar digabungkan menjadi satu kesatuan diantaranya sensor sebagai pembaca data, koneksi internet dengan bebarapa macam topologi jaringan, radio frequency identification (RFID), wireless sensor network dan teknologi yang terus akan bertambah sesuai dengan kebutuhan[5], sehingga dengan ini monitoring tidak hanya terbatas pada HMI.

Dari permasalahan yang dijelaskan, penulis melakukan penelitian dengan judul "Perancangan Sistem Monitoring Material Submerged Scraper Conveyor PT PJB UP Paiton 1-2 Berbasis Iot", yang bertujuan untuk memonitoring kondisi material bottom ash pada SSC secara real time dan dapat diakses dari manapun secara realtime.

\section{METODOLOGI}

Untuk menyelesaikan permasalahan ini digunakan model pengembangan Prototype. Model yang mudah dipahami dan mempunyai tahapan yang sederhana, sehingga prosedur pengembangan sistem yang akan dibuat menjadi lebih jelas pada tiap tahapannya. Adapun alur dari model pengembangan ini ditunjukkan pada flowchart alur model pengembangan berikut:[6]

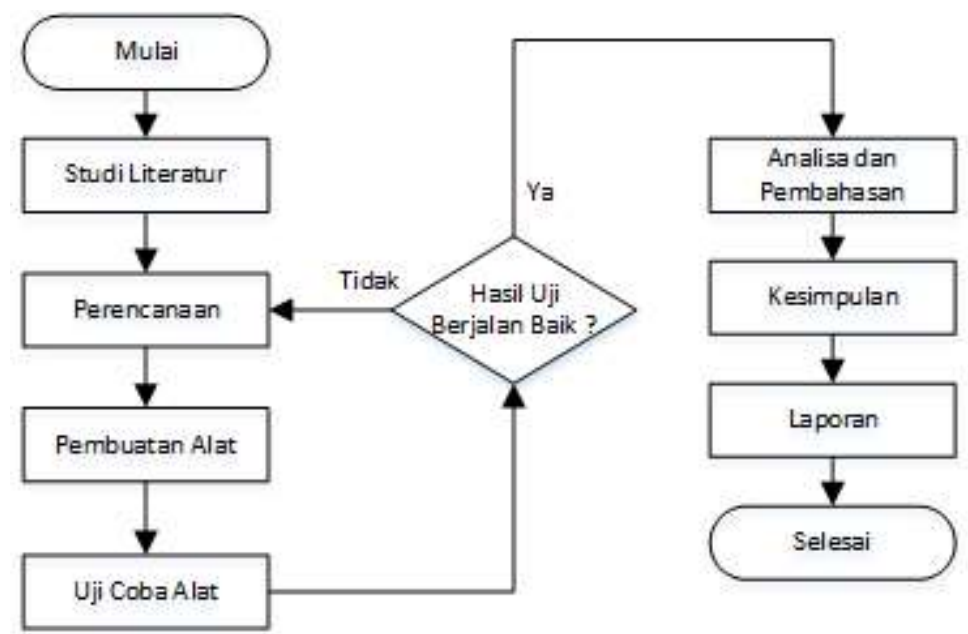

Gambar 1. Diagram Alur Penelitian[6]

\section{Studi Literatur}

Studi literatur dilakukan dengan kajian teori dan mencari referensi melalui jurnal, buku, dan lain-lain untuk bahan rujukan dan referensi dalam melakukan penelitian kemudian diamati korelasinya dengan permasalahan yang sedang diteliti.

\section{Perencanaan Alat}

a. ESP32 Dev Board

ESP32 adalah suatu chip pengendali dengan Wi-Fi 2,4 GHz dan Bluetooth mode ganda dirancang dengan teknologi TSMC berdaya rendah teknologi $40 \mathrm{~nm}$. yang dirancang dengan teknologi TSMC ultra-daya rendah $40 \mathrm{~nm}$. Dirancang untuk mencapai daya dan kinerja RF terbaik, ketahanan yang baik, serbaguna, dan andal dalam berbagai aplikasi dan profil daya yang berbeda[7].

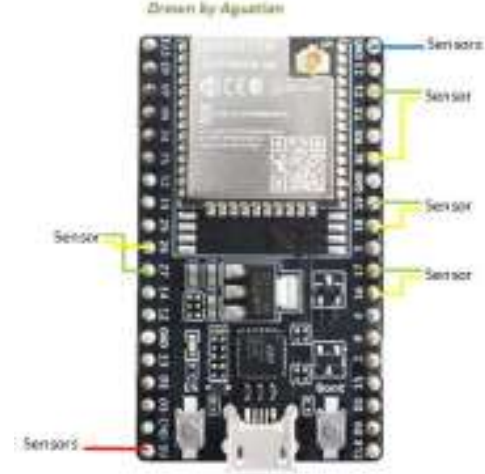

Gambar 2. ESP32 Dev Board 
ESP32 adalah solusi integrasi yang terbaik untuk aplikasi Wi-Fi + Bluetooth di industri IoT dengan kurang lebih 20 komponen eksternal. ESP32 mengintegrasikan sakelar antena, balun RF, penguat daya, penguat penerima dengan noise rendah, filter, dan modul manajemen daya.

\section{b. Sensor Ultrasonik HCSR04}

Sensor ultrasonik HCSR04 menggunakan sonar untuk pengukuran jaraknya. Menawarkan deteksi jarak tanpa kontak yang sangat baik dengan akurasi tinggi dan pembacaan yang stabil dalam sebuah paket easy to use. Jarak yang dapat diukur mulai dari $2 \mathrm{~cm}$ hingga $400 \mathrm{~cm}$ atau 1" hingga 13 kaki dan pengoperasiannya tidak terpengaruh oleh cahaya[8].

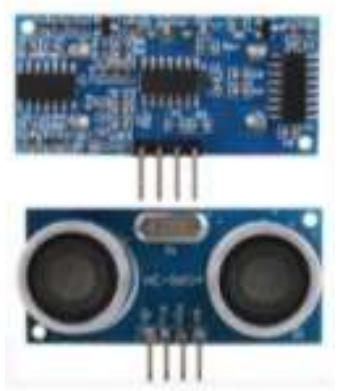

- Gambar 3. Sensor HC SR04

Features:

- Power Supply :+5V DC

- Quiescent Current : $<2 m A$

- Working Current: $15 \mathrm{~mA}$

- Effectual Angle: $<15^{\circ}$

-Ranging Distance : $2 \mathrm{~cm}-400 \mathrm{~cm} / \mathrm{l}^{\prime \prime}-13 \mathrm{ft}$

- Resolution : $0.3 \mathrm{~cm}$

- Measuring Angle: 30 degree

c. Ubidots Internet of Things (IoT) Platform

Ubidots memberikan solusi IoT end-to-end untuk memantau, mengontrol, dan mengotomatisasi proses jarak jauh untuk klien kesehatan serta startup yang didanai dan Fortune 1.000s di Amerika Tenggara dan di seluruh Amerika Latin[9].

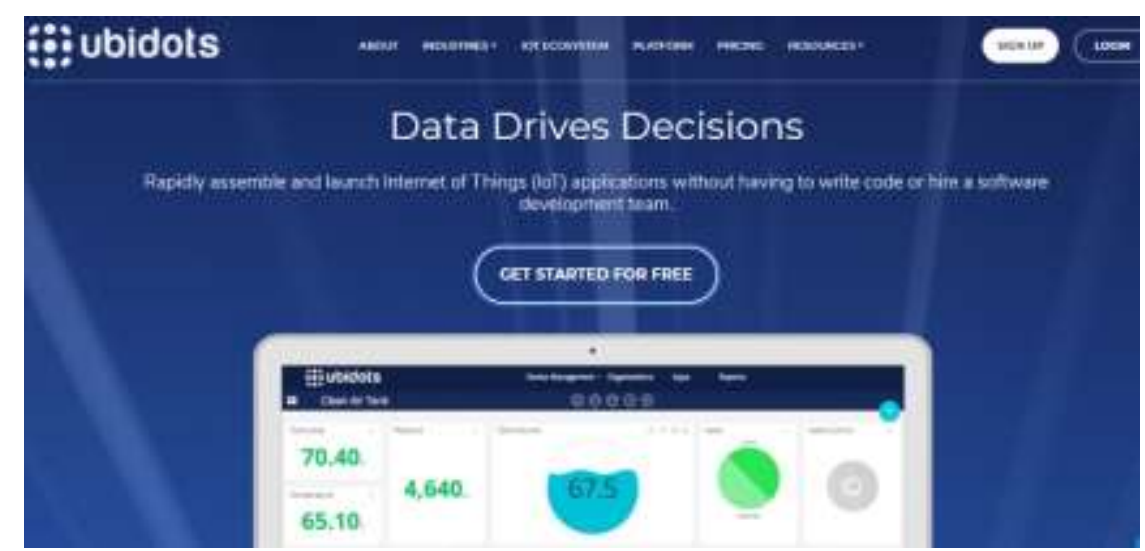

Gambar 4. Tampilan Awal Halaman Ubidots

Saat membangun sistem IoT berdasarkan sensor, dev board mengirimkan data ke platformcloud. Platform ini menyimpan data dan menggunakannya untuk membangun grafik[10]. Ubidots IoT cloud platform merupakan PaaS (Platform as a service) yang menyediakan beberapa layanan berguna dalam ekosistem IoT.

Layanan ini memungkinkan dev board membangun sebuah komunikasi jarak jauh melalui suatu penyedia layanan atau lintas penyedia layanan lainnya. Akan lebih mahal dan rumit bila secara terpisah menghubungkan suatu dev board ke server internet pada umumnya dari pada menggunakan sebuah platform IoT.

d. Telegram 
Untuk notifikasi, penulis menggunakan fitur yang telah disediakan oleh ubidots, yaitu mengirimkan notifikasi via telegram.

Telegram adalah aplikasi perpesanan yang fokus pada kecepatan dan keamanan, sangat cepat, sederhana, dan gratis. Anda dapat menggunakan Telegram di semua perangkat pada saat yang sama, pesan Anda disinkronkan secara mulus di sejumlah ponsel, tablet, atau komputer anda[11].

3. Desain dan Pembuatan Alat

1. Blok Diagram Fungsi

Blok diagram fungsional sistem yang dibuat pada perancangan ini secara umum dapat dilihat pada gambar di bawah

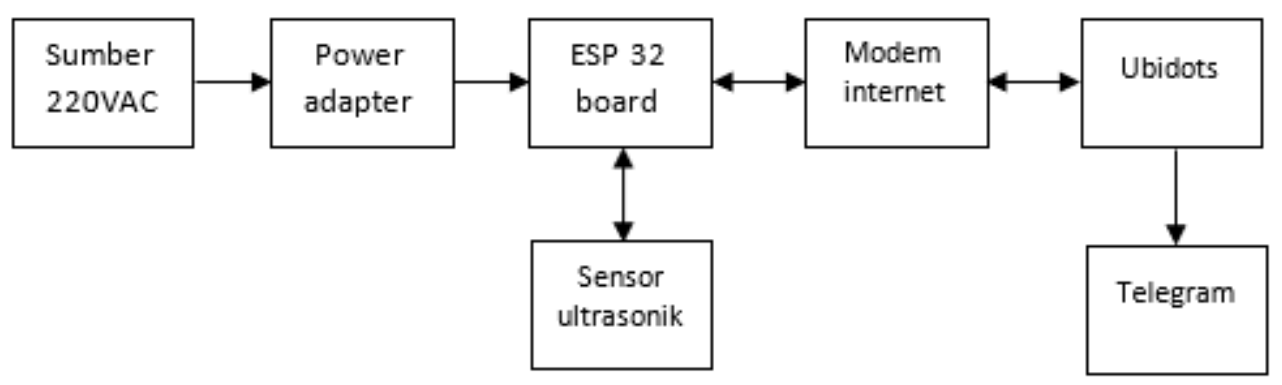

Gambar 5. Diagram Fungsional Sistem

4 buah sensor ultrasonik mengirimkan sinyal ping pada objek ukur (material pada scraper SSC), kemudian sinyal tersebut diproses oleh board ESP32 sehingga dihasilkan nilai ukur dalam centimeter. Nilai ukur tersebut dikirimkan ke server ubidots menggunakan jaringan internet modem yang sudah dihubungkan dengan board ESP32.Nilai ukur yang telah dikirim ke server ubidots kemudian diproses dan ditampilkan menjadi sebuah grafik multiple chart, masing-masing nilai ukur dari ke-empat sensor ultrasonik ditampilkan dengan warna line berbeda dalam 1 grafik, grafik dilengkapi fungsi waktu sehingga grafik bergerak seiring terus dikirimnya nilai pembacaan baru dari sensor ultrasonik. Kombinasi dari grafik garis dan fungsi waktu menghasilkan penggambaran grafik yang sesuai dengan gambaran kondisi material di lokal peralatan SSC.

2. Wiring Sistem Keseluruhan

Wiring sistem keseluruhan adalah penyambungan hardware secara keseluruhan yang meliputi perancangan wiring ESP32 board, sensor ultrasonik dan power adapter.

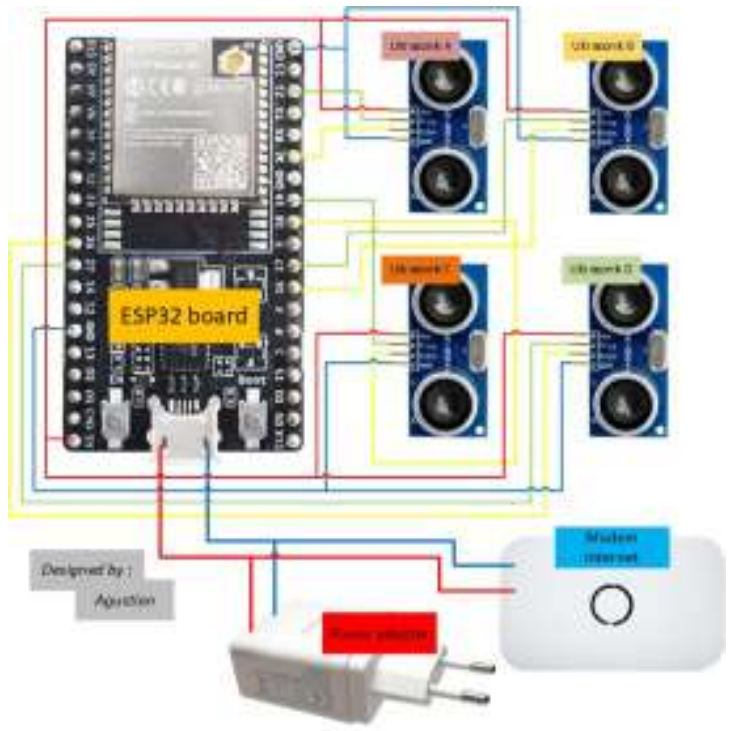

Gambar 6. Wiring Sistem Keseluruhan 


\section{Perancangan Tampilan Grafik Pada Ubidots}

Tampilan grafik dirancang agar sederhana dan mudah dimengerti oleh user/operator, grafik ini sebagai media interface antara alat dengan operator/user untuk monitoring. Nilai pembacaan sensor ultrasonik yang berhasil dikirim ke ubidots oleh Dev Board ESP32 digunakan sebagai variable yang akan dimasukkan dalam penampil grafik.

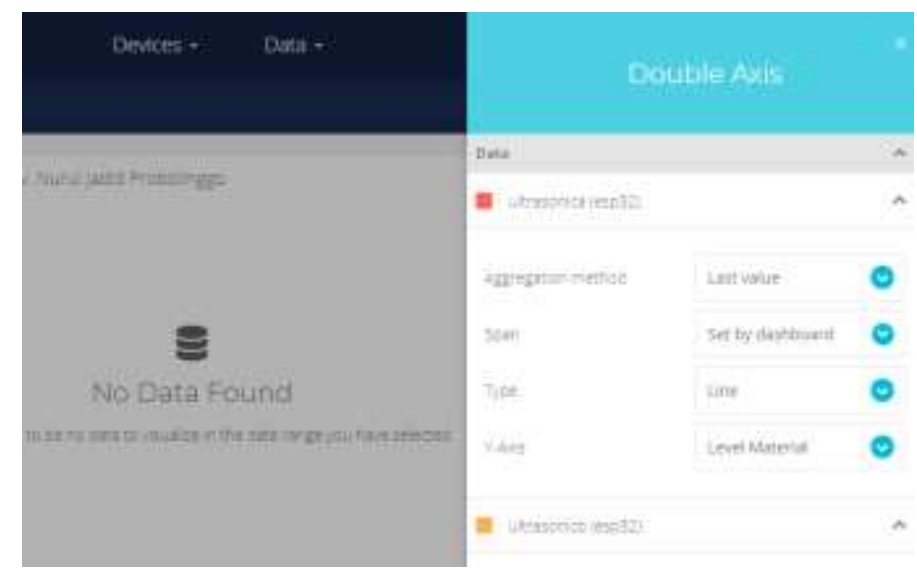

Gambar 7. Proses Perancangan Grafik Pada Ubidots

\section{Uji Coba Alat}

Pengujian alat dan sistem dilakukan untuk mengetahui apakah alat ini dapat bekerja dengan baik atau tidak. Pengujian ini meliputi dua pengujian, yakni pengujian alat dan sistem secara perangkat keras (hardware) dan perangkat lunak (software).

5. Hasil dan Pembahasan

Setelah melakukan uji coba akan dilakukan pembahasan untuk mengambil hasil dari pengujian alat dan sistem.

6. Kesimpulan

Pada proses ini alat dan sistem yang sudah dilakukan pembahasan dan hasil maka akan ditarik kesimpulan dan saran guna dilakukan pengembangan selanjutnya.

\section{HASIL DAN PEMBAHASAN}

Untuk mengetahui kinerja dari perancangan alat dan pembuatan sistem yang telah dirancang sebelumnya, maka diperlukan pengujian dan pembahasan dari setiap komponen yang dirancang agar dapat berjalan dengan baik dan sesuai dengan yang diharapkan. Adapun realisasi alat pada tugas akhir ini dapat dilihat pada Gambar 8 dan Gambar 9, ukuran box panel yang dipakai memiliki dimensi $15 \times 25 \times 5 \mathrm{~cm}$ dan housing sensor ultrasonik $6 \times 25 \times 3 \mathrm{~cm}$.

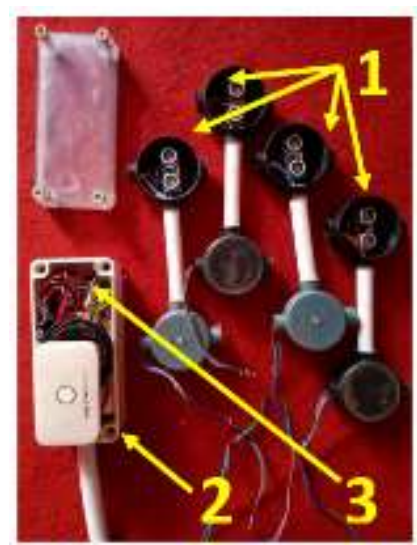

Gambar 8. Realisasi Alat Tampak Atas 
Keterangan :

1. Sensor ultrasonik dan housing

2. Box kontroler atau panel box

3. Kontroler ESP32

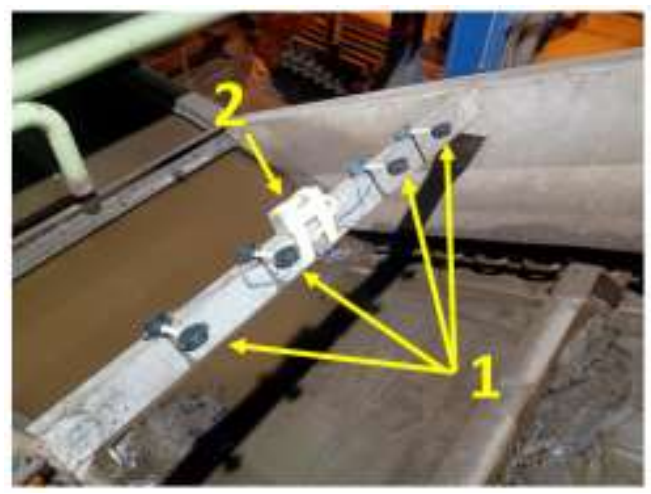

Gambar 9. Realisasi Alat Pada Lokal SSC PT PJB UP Paiton1-2

Keterangan :

1. Sensor ultrasonik

2. Panel box

1. Hasil Pengujian Dev Board ESP32

Pengujian ini bertujuan untuk menguji kemampuan board dalam menerima program dan mengaplikasikannya pada sensor-sensor yang dihubungkan, kemudian menguji koneksi dengan sinyal wifi yang telah disediakan.

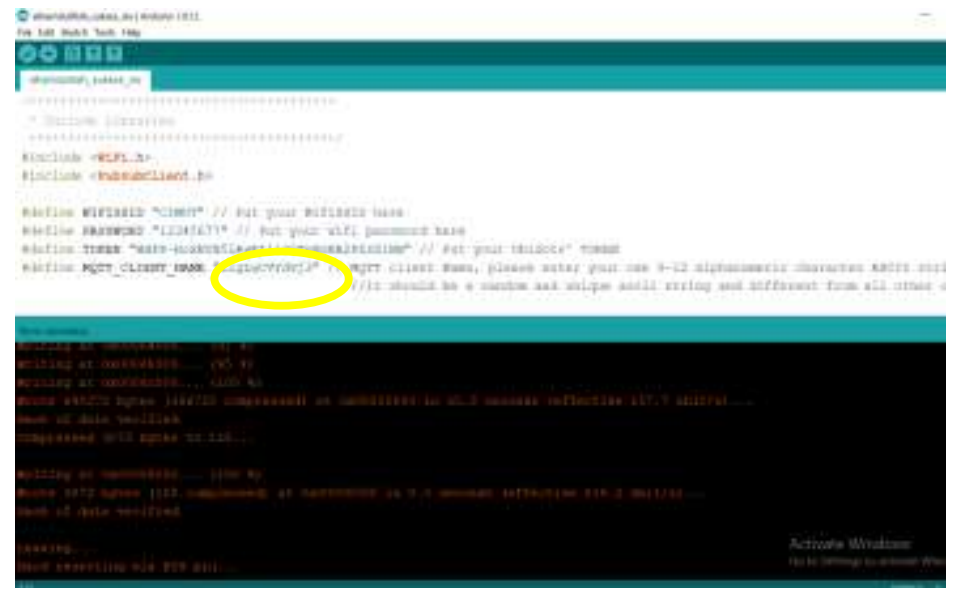

q Gambar 10. ESP32 Berhasil Menerima Program

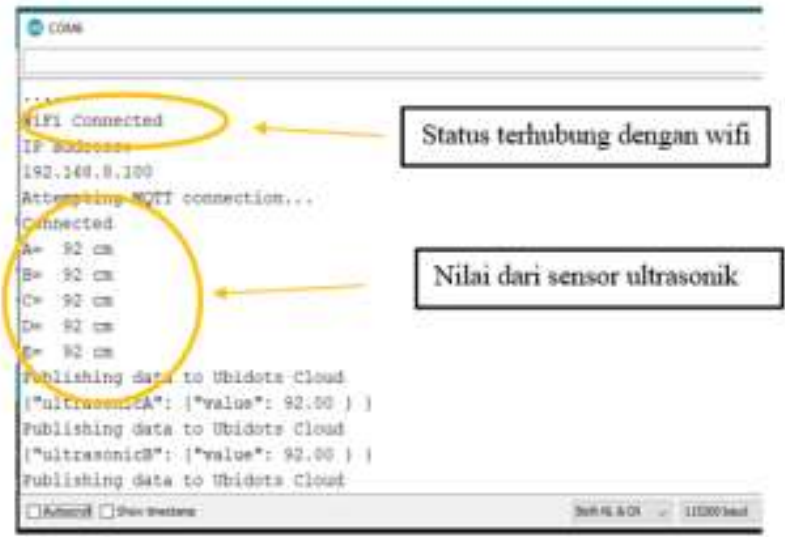

Gambar 11. ESP32 Berhasil Terhubung Dengan Wifi 
Dari gambar 10 di atas terlihat status "done uploading.." yang berarti bahwa board ESP32 berhasil menerima program dan pada gambar 11 terlihat bahwa board ESP32 berhasil terhubung dengan wifi dan juga berhasil menampilkan nilai dari sensor ultrasonik.

2. Hasil Pengujian Sensor Ultrasonik HCSR04

Pengujian sensor ultrasonik bertujuan untuk mengetahui keakuratan dan konsistensi sensor, sehingga dipastikan sensor yang digunakan benar-benar berfungsi dengan baik sesuai rancangan sistem.

Pengujian dilakukan dengan cara menempatkan objek ukur pada jarak yang tetap, sensor dihubungkan dengan board ESP32 dan PC untuk mengamati hasil pengukuran melalui serial monitor aurduino IDE.

hasil pengukuran 4 sensor ultrasonik yaitu sensor B,C,D dan E sebanyak 5 kali dengan jarak yang berbeda. Didapatkan akurasi pengukuran hingga $\pm 2 \mathrm{~cm}$, nilai error didapatkan dengan rumus sebagai berikut

$$
\text { Error }(\%)=\frac{\text { selisih hasil pembacaan }}{\text { Hasil pembacaan meteran }} \times 100 \%
$$

Tabel 1. Pengujian sensor ultrasonik B

\begin{tabular}{|c|c|c|c|c|}
\hline \multirow[b]{2}{*}{$\begin{array}{c}\text { Pengujian } \\
\text { ke }\end{array}$} & \multicolumn{2}{|c|}{ Hasil pembacaan } & \multirow[b]{2}{*}{ Selisih } & \multirow[b]{2}{*}{$\begin{array}{l}\text { Besar } \\
\text { error } \\
(\% /)\end{array}$} \\
\hline & $\begin{array}{l}\text { Roll } \\
\text { Meter } \\
(\mathrm{cm})\end{array}$ & $\begin{array}{c}\text { Ultrasonik } \\
\text { B (cm) }\end{array}$ & & \\
\hline 1 & 25 & 25 & 0 & 0.0 \\
\hline 2 & 35 & 34 & 1 & 2.9 \\
\hline 3 & 45 & 45 & 0 & 0.0 \\
\hline 4 & 55 & 55 & 0 & 0.0 \\
\hline 5 & 65 & 65 & 0 & 0.0 \\
\hline \multicolumn{4}{|c|}{ Rata-rata } & 2.9 \\
\hline
\end{tabular}

Tabel 2. Pengujian sensor ultrasonik C

\begin{tabular}{|c|c|c|c|c|}
\hline \multirow[b]{2}{*}{$\begin{array}{l}\text { Pengujian } \\
\text { ke }\end{array}$} & \multicolumn{2}{|c|}{ Hasil pembacaan } & \multirow[b]{2}{*}{ Selisih } & \multirow[b]{2}{*}{$\begin{array}{c}\text { Besar } \\
\text { error } \\
(\% /)\end{array}$} \\
\hline & $\begin{array}{c}\text { Roll } \\
\text { Meter } \\
(\mathrm{cm})\end{array}$ & $\begin{array}{l}\text { Ultrasonik } \\
\text { B (cm) }\end{array}$ & & \\
\hline 1 & 25 & 25 & 0 & 0.0 \\
\hline 2 & 35 & 35 & 0 & 0.0 \\
\hline 3 & 45 & 45 & 0 & 0.0 \\
\hline 4 & 55 & 55 & 0 & 0.0 \\
\hline 5 & 65 & 64 & 1 & 1.6 \\
\hline \multicolumn{4}{|c|}{ Rata-rata } & 1.6 \\
\hline
\end{tabular}

Tabel 3. Pengujian sensor ultrasonik D

\begin{tabular}{|c|c|c|c|c|}
\hline \multirow[b]{2}{*}{$\begin{array}{c}\text { Pengujian } \\
\text { ke }\end{array}$} & \multicolumn{2}{|c|}{ Hasil pembacaan } & \multirow[b]{2}{*}{ Selisih } & \multirow[b]{2}{*}{$\begin{array}{c}\text { Besar } \\
\text { error } \\
(\% /)\end{array}$} \\
\hline & $\begin{array}{l}\text { Roll } \\
\text { Meter } \\
(\mathrm{cm})\end{array}$ & $\begin{array}{c}\text { Ultrasonik } \\
\text { B (cm) }\end{array}$ & & \\
\hline 1 & 25 & 23 & 2 & 8.7 \\
\hline 2 & 35 & 34 & 1 & 2.9 \\
\hline 3 & 45 & 45 & 0 & 0.0 \\
\hline 4 & 55 & 53 & 2 & 3.8 \\
\hline 5 & 65 & 54 & 1 & 1.9 \\
\hline \multicolumn{4}{|c|}{ Rata-rata } & 3.46 \\
\hline
\end{tabular}


- Tabel 4. Pengujian sensor ultrasonik E

\begin{tabular}{|c|c|c|c|c|}
\hline \multirow[b]{2}{*}{$\begin{array}{l}\text { Pengujian } \\
\text { ke }\end{array}$} & \multicolumn{2}{|c|}{ Hasil pembacaan } & \multirow[b]{2}{*}{ Selisih } & \multirow[b]{2}{*}{$\begin{array}{l}\text { Besar } \\
\text { error } \\
(\% /)\end{array}$} \\
\hline & $\begin{array}{c}\text { Roll } \\
\text { Meter } \\
(\mathrm{cm})\end{array}$ & $\begin{array}{c}\text { Ultrasonik } \\
\text { B (cm) }\end{array}$ & & \\
\hline 1 & 25 & 24 & 1 & 4.2 \\
\hline 2 & 35 & 34 & 1 & 2.9 \\
\hline 3 & 45 & 45 & 0 & 0.0 \\
\hline 4 & 55 & 54 & 1 & 1.9 \\
\hline 5 & 65 & 65 & 0 & 0.0 \\
\hline \multicolumn{4}{|c|}{ Rata-rata } & 1.8 \\
\hline
\end{tabular}

\section{Hasil Pengujian Antar Muka Ubidots}

Tujuan pengujian ini adalah untuk memastikan server ubidots dapat sinkron dengan hardware dan antarmuka ubidots telah sesuai dengan rancangan sistem. Ke-empat sensor ultrasonik dihubungkan dengan board ESP32, kemudian board ESP32 dihubungkan dengan PC untuk menampilkan serial monitor pada Arduino IDE.

Jarak penempatan sensor ultrasonik dengan dasar SSC adalah $92 \mathrm{~cm}$. Untuk menguji fungsi notifikasi saat terdeteksi level material tinggi ( $>50 \mathrm{~cm}$ dari dasar SSC), sensor ultrasonik diberikan penghalang dengan jarak 5-40 $\mathrm{cm}$ dari sensor sebagai simulasi terdeteksinya material dengan tinggi $>50 \mathrm{~cm}$ dari dasar SSC.

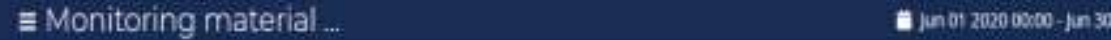

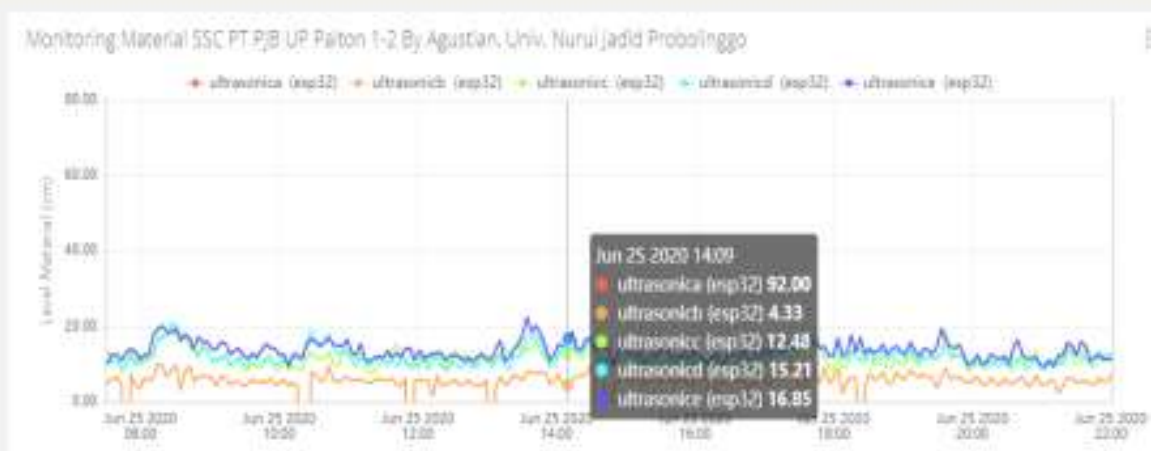

-Gambar 12. Widget Grafik Monitoring Material SSC PT PJB UP Paiton 1-2

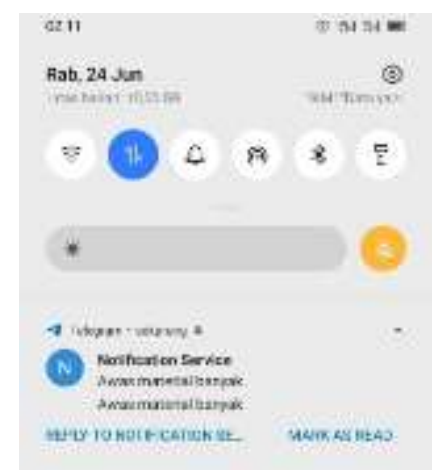

Gambar 13. Notifikasi Telegram Saat Material Tinggi

Widget grafik monitoring material SSC PT PJB UP Paiton 1-2 berhasil ditampilkan pada dashboard dan telah sesuai dengan rancangan sistem, seperti yang ditampilkan pada Gambar 12, kemudian dari Gambar 13 diketahui bahwa platform ubidots juga berhasil mengirimkan notifikasi via telegram saat level material yang melewati sensor ultrasonik $>50 \mathrm{~cm}$. 


\section{Hasil Lifetest Keseluruhan Sistem}

Untuk menjamin keseluruhan sistem monitoring material SSC PT PJB UP Paiton 1-2 berfungsi dengan baik dan handal, perlu dilakukan life test alat di lapangan selama setidaknya tidak kurang dari 8 jam (1 periode shift operator PT PJB UP Paiton 1-2 adalah 8 jam).

Alat dipasang pada pangkon atas bak scraper SSC dan diaktifkan selama $>8$ jam nonstop, grafik hasil pembacaan alat dipantau melalui PC CCR Ash Handling atau pada smartphone pribadi, penulis melakukan pengujian life test selama 3x, yaitu pada tanggal 20 Juni 2020 selama 14 jam, tanggal 24 Juni 2020 selama 8.5 jam dan terakhir pada tanggal 25 Juni 2020 selama 16.5 jam.

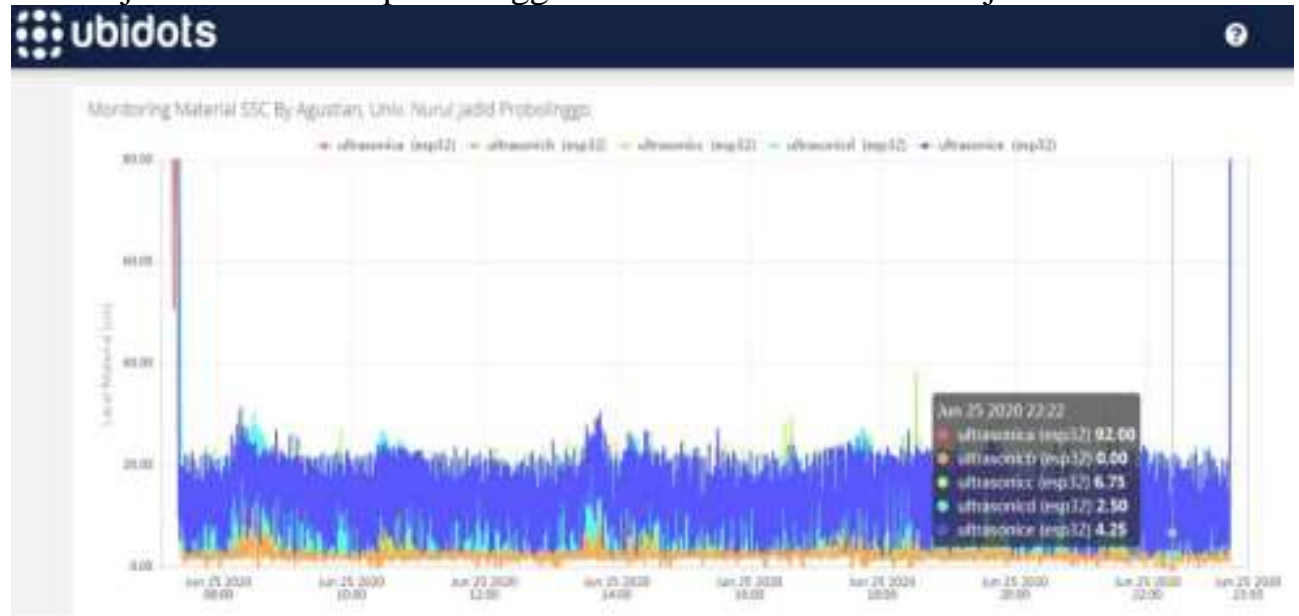

Gambar 14. Grafik monitoring material SSC selama life test 15 jam

\section{KESIMPULAN}

Kesimpulan yang dapat diambil berdasarkan hasil pengujian dan pembahasan yang dilakukan adalah sebagai berikut:

1. Alat sistem monitoring material SSC PT PJB UP Paiton 1-2 telah dapat dirancang dan penampilan grafik pada platform Ubidots melalui web berhasil ditampilkan dan dapat diakses dari manapun secara online.

2. Peralatan terdiri dari rangkaian utama yaitu, board ESP32 sebagai kontroler, sensor ultrasonik HCSR04 sebagai sensor jarak, power adapter sebagai penyedia daya dan internet modem sebagai penghubung alat dengan server ubidots. Semua peralatan sudah bekerja sesuai perancangan.

3. Alat dapat dipakai nonstop selama $>8$ jam dan akurasi pengukuran mencapai $\pm 2 \mathrm{~cm}$

4. Alat berhasil mengirimkan notifikasi via telegram saat level material tinggi ( $>50 \mathrm{~cm}$ dari dasar $\mathrm{SSC}$ )

\section{DAFTAR PUSTAKA}

[1] B. S. Management, "Info PJB," Bidang Stakeholder Management PT PJB, Surabaya, pp. 1-48, 2018.

[2] System Owner PT PJB UP Paiton, "2. Notulen pembahasan RCFA SSC Unit 1 trip.pdf," Paiton, Kab. Probolinggo, 2019.

[3] F. Basim Ismail, E. Why Siew Kuan, and M. Shakir Nasif, "Development and implementation of bottom ash crushing system in Submerged Scrapper Conveyor (SSC) for Coal-fired Power Plant," MATEC Web Conf., vol. 131, pp. 1-6, 2017, doi: 10.1051/matecconf/201713103002.

[4] B. A. Mir and A. Malik, "Studies on the Mechanical Behavior of Bottom Ash for a Sustainable Environment," Int. J. Civ. Environ. Eng., vol. 11, no. 7, pp. 857-863, 2017.

[5] M. T. Okano, "IOT and Industry 4.0: The Industrial New Revolution," ICMIS-17 - Int. Conf. Manag. Inf. Syst., no. September, pp. 75-82, 2017.

[6] T. S. Jaya and D. K. Widyawati, "Pengembangan E-Market Place Pertanian Dengan Metode Prototype Development of Agricultural E-Marketplace By Prototype Method," Pros. Semin. Nas. Pengemb. Teknol. Pertan., pp. 27-34, 2019.

[7] Broadcom, "Hardware Design Guidelines Design Guide," 2019.

[8] C. T. Sdn, "Product User's Manual-HC-SR04 Ultrasonic Sensor User's Manual Product User's Manual-HC-SR04 Ultrasonic Sensor Index," no. May, pp. 1-10, 2013.

[9] ubidots, "Company About," ubidots.com, 2012. [Online]. Available: ubidots.com. [Accessed: 18-Jul-2020]. 
[10] S. Siddagangaiah, "A Novel Approach to IoT Based Plant Health Monitoring System," Int. Res. J. Eng. Technol., vol. 3, no. 11, pp. 880-886, 2016.

[11] Telegram.org, "What is Telegram ?," Telegram.org. [Online]. Available: telegram.org/faq. [Accessed: 19-Oct-2020]. 